\title{
PERSPECTIVE OPEN Role of proteins in the degradation of relatively inert alloys in the human body
}

\author{
Yolanda S. Hedberg (1D
}

Many biomedical materials used today for applications such as orthopedic, dental, and cardiovascular implants and devices are made of corrosion-resistant, 'inert', metallic materials of the cobalt-chromium, titanium, and stainless steel alloy groups. This perspective focuses on the role of proteins in the degradation of these materials in a human body environment. After adsorption, the proteins interact relatively slowly with the metal and metal surface oxide. A number of factors, including the individual body chemistry (especially the presence of inflammatory cells producing oxidative species), determine whether the proteins can bind to metals in the surface oxide and whether the metal-protein conjugates can detach from the surface. Metals in the forms of proteinbound metal ions or nanosized particles can also increase protein-protein interactions and aggregation, which can cause some health effects and change the material degradation mechanism. While proteins in some short-term studies $(<6 \mathrm{~h})$ even decrease material degradation due to shielding effects and better lubrication, they may increase degradation after longer time periods due to relatively slow binding, detachment, and combined corrosion processes. In-vitro material degradation studies of relatively corrosion-resistant alloys for biomedical applications should therefore include long-term studies, complexing agents or proteins, and realistic oxidative environments simulating inflammatory conditions.

npj Materials Degradation (2018)2:26; doi:10.1038/s41529-018-0049-y

\section{INTRODUCTION}

Replacement of human organs, bones, and teeth is challenging even though engineers and physicians have attempt to find ideal replacement materials for decades, if not centuries. Metals and alloys are used today for the replacement of, or functional parts for, orthopedic, dental, spinal, cardiovascular, neurological, and gynecological implants, or for fracture fixation. ${ }^{1}$ In most of these applications, materials with the highest possible corrosion resistance, so-called inert materials, are used today. For metallic materials these are mainly titanium, cobalt-chromium, and stainless steel alloys. These will be the focus of this perspective. Still, there exists no material that is as good as the natural material in the human body, regarding all the requirements for mechanical properties, corrosion resistance, biocompatibility, hardness, density, and toxic properties. ${ }^{2}$ It has been known that the human body is a very corrosive environment resulting in a large range of different and combined corrosion types. Those are influenced by wear, fretting, crevices, fatigue, salts, and inappropriate geometry of implants. ${ }^{3-6}$ Recent findings highlight the importance of inflammatory cells, individual body chemistry, Fenton chemistry, and electrosurgery. ${ }^{1,7-10}$ In all, it becomes increasingly clear that accelerated corrosion tests or immersion tests in simple solutions (simulating the ionic strength, chloride content, and $\mathrm{pH}$ of physiological conditions) are insufficient to predict corrosion observed in-vivo. ${ }^{2}$ This perspective will focus on the role of proteins for material degradation of 'inert' metal and alloy degradation by providing some insights into surface and colloid chemistry, degradation kinetics, and metal-protein interactions that are crucial to understand and design predictive and comparative corrosion and metal release experiments for biomedical metallic 'inert' materials.

\section{FAST AND SLOW KINETICS OF METAL-PROTEIN INTERACTIONS} Adsorption

Most proteins adsorb relatively rapidly (seconds to hours) on metal and alloy surfaces in physiological environments of relatively high ionic strength, even when the protein and the surface are similarly charged. ${ }^{11}$ The kinetics of adsorption, and the competition among different proteins, are highly influenced by the surface properties of the metal/alloy, such as surface energy, charge, roughness, hydrophobicity, and thickness of its surface oxide. $^{11-14}$ Protein properties influencing the adsorption are protein size, charge, hydrophobicity, and concentration; solution properties important for adsorption inside the human body are, e.g., ionic strength, $\mathrm{pH}$, shear rates, and agitation. ${ }^{15}$ Adsorption as the first step of metal-protein interaction is important for material degradation in several ways: (i) it may inhibit cathodic reactions and initial corrosion similar to a coating (Fig. 1a); (ii) it mediates cell adsorption ${ }^{16}$ (Fig. 1f); and (iii) it can act as a lubricant for surfaces that are exposed to friction and fretting (Fig. 1b). Most of these effects decrease material degradation initially. Hence, this is the conclusion of several, but not all, short-term (a few hours) studies. ${ }^{17,18}$ However, appearances can be deceiving.

Protein-metal binding and detachment

Many proteins bind to metals at specific binding sites and additionally by weak interactions like electrostatic interactions.

\footnotetext{
'Division of Surface and Corrosion Science, Department of Chemistry, School of Engineering Sciences in Chemistry, Biotechnology and Health, KTH Royal Institute of Technology, Drottning Kristinas väg 51, SE-10044 Stockholm, Sweden

Correspondence: Yolanda S. Hedberg (yolanda@kth.se)
}

Received: 3 June 2018 Revised: 23 July 2018 Accepted: 20 August 2018

Published online: 07 September 2018 


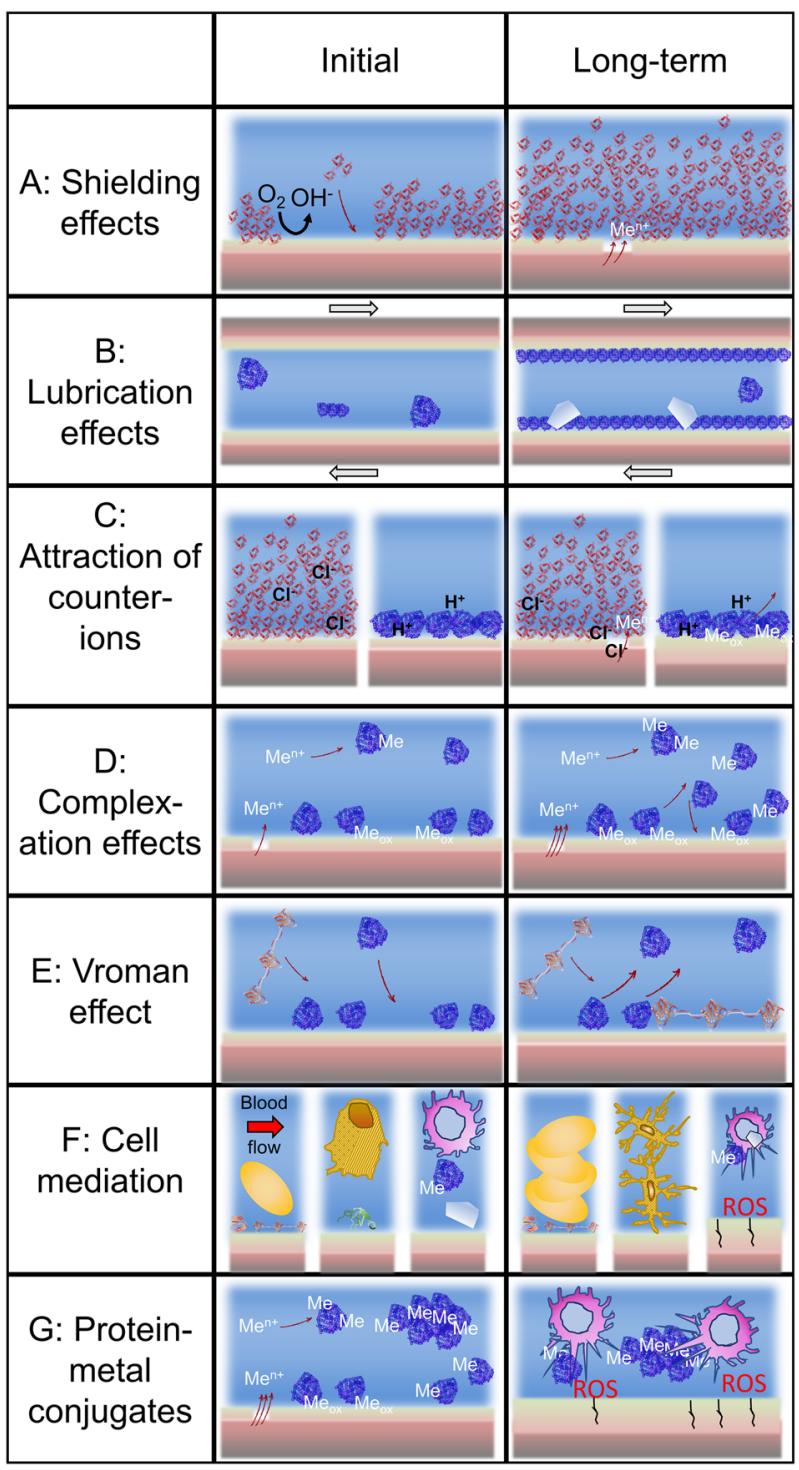

Albumin was identified as the strongest metal binder of human blood proteins. ${ }^{19}$ This protein was also found to induce the strongest metal release and corrosion among several other proteins investigated for stainless steel AISI 316L. ${ }^{13,20}$ Albumin is also present at relatively high concentration in synovial (joint) fluid. ${ }^{21}$ Protein binding to metal atoms in metal oxides is however strongly dependent on the surface oxide properties and will only occur if the protein-metal bond is stronger than metal-oxide or metalhydroxide bonds or if those bonds are weakened by defects. Weakening of the metal-oxide bonds by metal-protein complexes is often a very slow process and, in several cases, depends on the presence of other factors. If the metal-protein complex weakens the metal-oxide bonds, the metal-protein complex could eventually detach from the surface oxide (an even slower process). ${ }^{12,13}$ This is facilitated by high driving forces for protein exchange (high concentration of proteins, agitation, high ionic strength), which often are present in the human body environment. The Vroman effect, ${ }^{22}$ that is the replacement of a surface-bound protein by a protein with larger surface binding affinity (Fig. 1e), also facilitates the detachment of metal-protein conjugates. Both metal-protein binding and metal-protein conjugate surface detachment are highly dependent upon a number of factors, such as, the alloy composition and surface oxide composition, crystallinity, heterogeneity, and
Fig. 1 Schematic illustration of the effect of proteins on material degradation, exemplifying six different effects as a function of time. Note that the time window for initial and long-term processes strongly depends on prevailing material, environmental, and physiological conditions and can range from milliseconds to years. a Shielding effects may initially decrease material degradation by decreasing cathodic reactions and may increase material degradation after longer time by localized corrosion. b Lubrication by proteins initially decreases friction; trapping of wear particles in the protein layer or protein aggregates may increase friction ${ }^{46}$; a tightly packed protein layer may decrease friction and wear. ${ }^{44,45}$ C Attraction of counter-ions may result in weakening of the oxide or localized corrosion. $\mathbf{d}$ Complexation of metal species to proteins can occur in solution, directly at the metal or metal oxide/hydroxide. Complexation can result in increased corrosion/dissolution rates and detachments of protein-metal conjugates. e The Vroman effect causes an exchange of adsorbed proteins and can thereby increase the dissolution/corrosion rate by the detachment of metal-bound proteins or influence it by a change of shielding effects. $f$ Three examples of protein-mediated cell events of large importance for biomedical materials: left: platelet coagulation mediated by several proteins (for e.g., Von Willebrand factor, fibronectin, fibrinogen) ${ }^{49}$; middle: adsorption of bone cells and osseointegration of implants is mediated by proteins (here, fibronectin) ${ }^{16}$; right: immunological and inflammatory reactions are triggered by metal-protein conjugates and wear particles, and can result in increased inflammatory and oxidative conditions increasing material degradation. $\mathbf{g}$ Metal-protein conjugates can result in immunological (allergic) reactions or the formation of large-sized (several hundred nanometer or micrometer-sized) protein aggregates that trigger immunological and inflammatory reactions, which result in increased material degradation. Me metal, ROS reactive oxygen species

defect density. In contrast to corrosion in terms of metal oxidation, which is decreased for amorphous oxides as compared to crystalline oxides, $^{23,24}$ amorphous surface oxides increase the protein-induced dissolution due to an enhancement of the metal complexation and detachment $^{24,25}$ (Fig. 1d). The reason is most probably a weaker metal-oxide bond (larger atomic distance) in amorphous as compared to crystalline oxides. The surface oxide of titanium alloys belongs to one of the most chemically stable oxides. However, it is affected negatively by proteins in the presence of hydrogen peroxide or upon oxidation. ${ }^{26-30}$ Enhanced corrosion and metal release in the presence of proteins have been observed after a few hours at the shortest (for stainless steel AISI 316 in phosphate buffered saline, $\mathrm{pH}$ $7.4)^{12}$ and can occur after significantly longer times, e.g., after at least $24 \mathrm{~h}$ for a titanium-aluminum-vanadium alloy in the presence of hydrogen peroxide, which can form complexes with titanium in the surface oxide. ${ }^{27,30}$ Interestingly, the metal release pattern in one of these harsh in-vitro studies combining proteins and hydrogen peroxide $^{30}$ was similar to that observed in-vivo in rat tibia tissue. ${ }^{31}$ Hence, in certain environments there is a transition from an initially beneficial effect of proteins to a detrimental effect for material degradation (Fig. 1). This transition occurs in most cases only after several hours and might therefore be missed in the majority of shortterm studies. A long-term (48 weeks) study investigating the metal release from a titanium-aluminum-vanadium alloy in rat tibia tissue showed a stabilization or decrease of metals in tissue after about 6-24 weeks. ${ }^{31}$ Also, from the evidence that exists on metal oxide interactions with complexing agents, 25,32 and from the similarity of complexing agents and proteins in terms of dissolution, ${ }^{12,33,34}$ it seems clear that at least some proteins can directly interact with the metal oxide (Fig. 1d), which is different from what is claimed in ref. ${ }^{35}$. However, direct protein interactions with the metal (not the oxide), especially for defective oxides or under fretting conditions, are more rapid (Fig. 1d) and can increase the dissolution/corrosion rate at nonpassive conditions. This could be responsible for the increased nickel to chromium ratio ${ }^{20,36}$ in the release of metals from stainless steel in 


\section{Synergistic effects (increased degradation)}

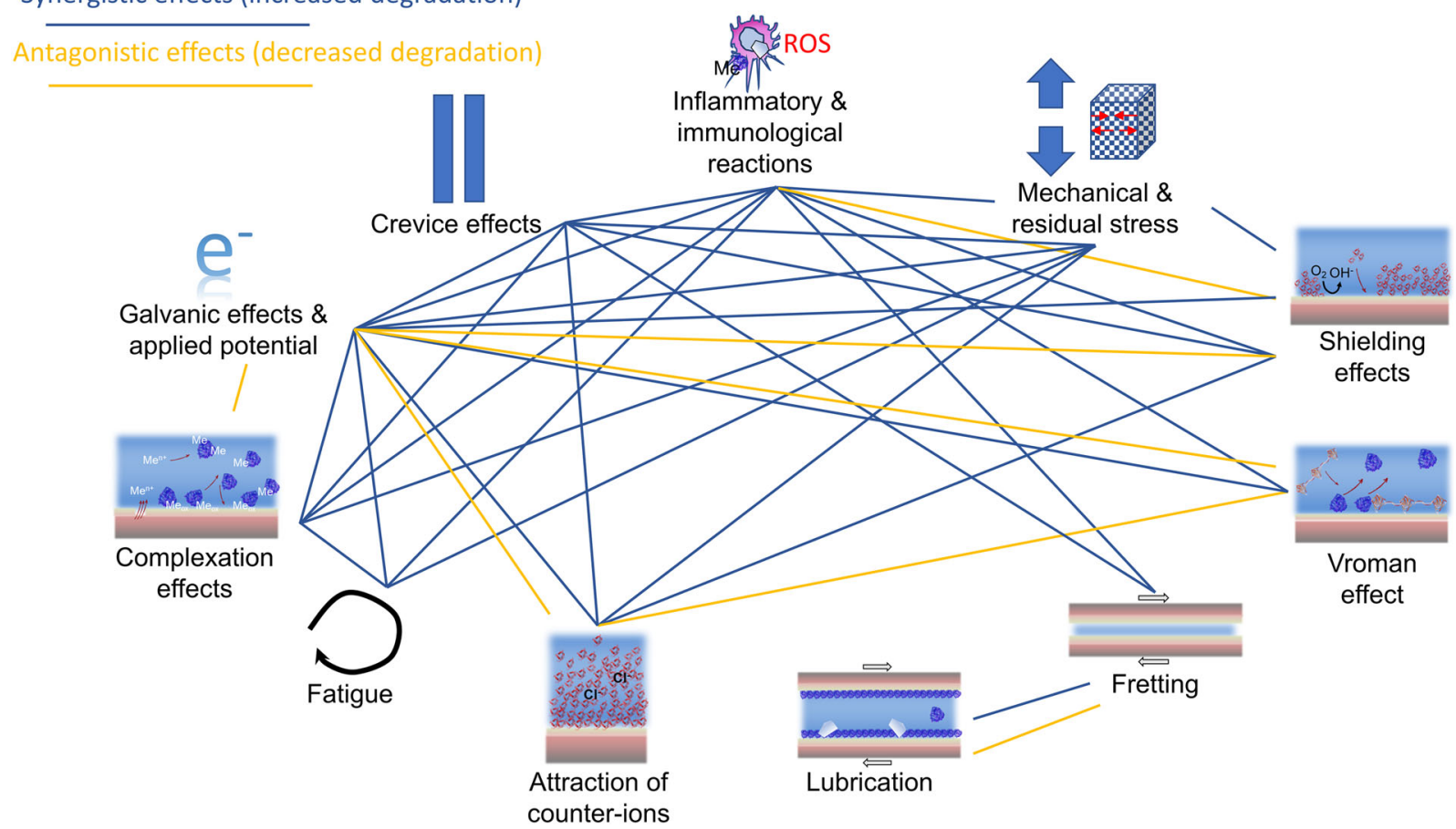

Fig. 2 Examples of synergistic and antagonistic combinations of different effects/factors. Synergistic effects is the combined effect and is greater than the sum of single effects, and for antagonistic combinations the combined effect may decrease material degradation compared with single effects. Most combined effects increase the extent of material degradation synergistically. The examples of antagonistic combinations are: (i) adsorbed protein layers shielding cathodic reactions or reactive oxygen species may decrease the effect of inflammatory conditions; (ii) the exchange of proteins by the Vroman effect may decrease the effect that attracted counter-ions may have locally; (iii) a protein-induced decrease of friction by lubrication or tightly packed layers may decrease fretting-induced corrosion; ${ }^{4,45}$ and (iv) electricallycoupled different materials or applied potential (e.g., from electronic devices, electrosurgery) may change the amount and type of adsorbed proteins and hence related effects ${ }^{14}$

the presence of albumin, as nickel metal is enriched beneath the surface oxide, which usually does not contain nickel. ${ }^{37}$ The attraction of counter-ions by adsorbed proteins, that is, anions (such as chlorides) for net positively charged adsorbed proteins (e.g., lysozyme at $\mathrm{pH}$ 7.4) and cations (such as protons) for net negatively charged adsorbed proteins (e.g., albumin), might further weaken the surface oxide and result in localized corrosion (Fig. 1alRef/>c). ${ }^{20}$

\section{METAL-INDUCED PROTEIN-PROTEIN INTERACTIONS}

Protein-metal interactions do not only have consequences for material degradation but also directly for health and protein-protein interactions. Metal-protein conjugates can act as allergens, by either sensitizing the immune system or eliciting cell-mediated immunological reactions (Fig. 1g). ${ }^{38}$ Further, metal ions or nanosized metal-containing particles can induce increased protein-protein interactions, which result in aggregated protein particles (Fig. 1g). ${ }^{39-41}$ These protein particles can have negative health effects, ${ }^{42}$ or result in an increased coefficient of friction ${ }^{43}$ or inflammatory conditions, which may impact the material degradation negatively, e.g., by increased inflammatory (oxidative) conditions (Fig. 1g). Although proteins or protein layers act as lubricants under friction or reduce the wear, ${ }^{44,45}$ it has been suggested that they retain abrasive particles and thereby increase the total wear (Fig. 1b). ${ }^{46}$

\section{COMBINED MECHANISMS OF MATERIAL DEGRADATION IN- VIVO}

It is clear from most recent literature within this field, mainly thanks to retrieval studies of implants observing 'impossible' corrosion types, that many combined mechanisms of material degradation exist involving friction and fatigue-induced degradation, Fenton chemistry and highly oxidative environments, chemical dissolution, and crevice/pitting corrosion (Fig. 2). ${ }^{1,2,5,6,10}$ Most of these combined mechanisms increase the extent of corrosion as compared to a single factor or type of mechanism.

A recent study on particles released from implant materials into tissues found that chromium in some particles in the tissues (for some patients) was oxidized to the hexavalent chromium form. ${ }^{47}$ This finding further strengthens the view of the importance of individual human body chemistry and that inflammatory/infectious conditions due to oxidative species highly influence corrosion. This individual body response depends on the extent and particle characteristics of released wear particles. It has been shown for a range of metallic materials and alloys that their wear particles cause increased inflammatory or toxic responses, while their corresponding bulk materials are biocompatible. ${ }^{48}$

\section{OUTLOOK}

This perspective highlights the importance of time, complexing agents, proteins, and oxidative conditions (ideally in a combined way) for in-vitro material testing for biomedical applications. Protein-induced degradation includes slow chemical and combined processes, which may require different experimental approaches than for traditional corrosion testing. The combined effect of protein- and hydrogen peroxide-induced degradation of titanium alloys should be investigated further for other oxidative species and alloys. The development of new in-vitro material degradation study protocols for relatively corrosion-resistant alloys for biomedical applications should also consider long-term studies, complexing agents (like citrate) or proteins (like albumin), and realistic oxidative environments simulating inflammatory 
conditions. Worst case combinations of influencing factors should be used to simulate the complex environment in the human body.

\section{ACKNOWLEDGEMENTS}

The authors acknowledge Swedish Research Council for financial support, and Dr. J. Hedberg and Prof. B. Lyne for reading and commenting the manuscript. This work was supported by the Swedish Research Council (Grant no. 2015-04177).

\section{AUTHOR CONTRIBUTIONS}

Y.S.H. wrote the manuscript

\section{ADDITIONAL INFORMATION}

Competing interests: The authors declare no competing interests.

Publisher's note: Springer Nature remains neutral with regard to jurisdictional claims in published maps and institutional affiliations.

\section{REFERENCES}

1. Gilbert, J. Corrosion in the human body: metallic implants in the complex body environment. Corrosion 73, 1478-1495 (2017).

2. Milošev, I. From in vitro to retrieval studies of orthopedic implants. Corrosion 73, 1496-1509 (2017)

3. Pound, B. G. Corrosion behavior of metallic materials in biomedical applications. II. Stainless steels and Co-Cr alloys. Corros. Rev. 32, 21-41 (2014).

4. Pound, B. G. Corrosion behavior of metallic materials in biomedical applications. I. Ti and its alloys. Corros. Rev. 32, 1-20 (2014).

5. Teoh, S. Fatigue of biomaterials: a review. Int J. Fatigue. 22, 825-837 (2000).

6. Maurer-Ertl, W. et al. Recall of the ASR XL head and hip resurfacing systems. Orthopedics 40, e340-e347 (2017).

7. Liu, Y. \& Gilbert, J. L. The effect of simulated inflammatory conditions and Fenton chemistry on the electrochemistry of CoCrMo alloy. J. Biomed. Mater. Res. B 106, 209-220 (2018).

8. Kubacki, G. W., Sivan, S. \& Gilbert, J. L. Electrosurgery induced damage to Ti-6Al$4 \mathrm{~V}$ and $\mathrm{CoCrMo}$ alloy surfaces in orthopedic implants in vivo and in vitro. J. Arthroplast. 32, 3533-3538 (2017).

9. Arnholt, C. M. et al. Corrosion damage and wear mechanisms in long-term retrieved $\mathrm{CoCr}$ femoral components for total knee arthroplasty. J. Arthroplast. 31, 2900-2906 (2016).

10. Igual Muñoz, A., Schwiesau, J., Jolles, B. M. \& Mischler, S. In vivo electrochemical corrosion study of a CoCrMo biomedical alloy in human synovial fluids. Acta Biomater. 21, 228-236 (2015).

11. Silva-Bermudez, P. \& Rodil, S. E. An overview of protein adsorption on metal oxide coatings for biomedical implants. Surf. Coat. Tech. 233, 147-158 (2013).

12. Hedberg, Y., Karlsson, M.-E., Blomberg, E., Odnevall Wallinder, I. \& Hedberg, J. Correlation between surface physicochemical properties and the release of iron from stainless steel AISI 304 in biological media. Colloid Surf. B 122, 216-222 (2014).

13. Hedberg, Y. et al. Interaction of albumin and fibrinogen with stainless steelinfluence of sequential exposure and protein aggregation on metal release and corrosion resistance. Corrosion 73, 1423-1436 (2017).

14. Igual Muñoz, A. \& Mischler, S. Electrochemical quartz crystal microbalance and Xray photoelectron spectroscopy study of cathodic reactions in bovine serum albumin containing solutions on a physical vapour deposition-CoCrMo biomedical alloy. Electrochim. Acta 180, 96-103 (2015).

15. Norde, W. Driving forces for protein adsorption at solid surfaces. Macromol. Symp. 103, 5-18 (1996).

16. Wilson, C. J., Clegg, R. E., Leavesley, D. I. \& Pearcy, M. J. Mediation of biomaterial-cell interactions by adsorbed proteins: a review. Tissue Eng. 11, 1-18 (2005).

17. Cortizo, M. C., de Mele, M. F. L. \& Cortizo, A. M. Metallic dental material biocompatibility in osteoblastlike cells. Biol. Trace Elem. Res. 100, 151-168 (2004).

18. Koronfel, M. A. et al. Understanding the reactivity of CoCrMo-implant wear particles. npj Mater. Degrad. 2, 8 (2018).

19. Merritt, K., Brown, S. \& Sharkey, N. The binding of metal salts and corrosion products to cells and proteins in vitro. J. Biomed. Mater. Res. 18, 1005-1015 (1984).

20. Hedberg, Y. et al. Surface-protein interactions on different stainless steel grades -effects of protein adsorption, surface changes and metal release. J. Mater. Sci. Mater. M. 24, 1015-1033 (2013).
21. Oates, K. M., Krause, W. E., Jones, R. L. \& Colby, R. H. Rheopexy of synovial fluid and protein aggregation. J. R. Soc. Interface 3, 167-174 (2006).

22. Hirsh, S. L. et al. The Vroman effect: competitive protein exchange with dynamic multilayer protein aggregates. Colloid Surf. B 103, 395-404 (2013).

23. Shih, C.-C., Lin, S.-J., Chung, K.-H., Chen, Y.-L. \& Su, Y.-Y. Increased corrosion resistance of stent materials by converting current surface film of polycrystalline oxide into amorphous oxide. J. Biomed. Mater. Res. 52, 323-332 (2000).

24. Hedberg, Y. \& Midander, K. Size matters: mechanism of metal release from $316 \mathrm{~L}$ stainless steel particles is governed by size-dependent properties of the surface oxide. Mater. Lett. 122, 223-226 (2014).

25. Carbonaro, R. F., Gray, B. N., Whitehead, C. F. \& Stone, A. T. Carboxylate-containing chelating agent interactions with amorphous chromium hydroxide: adsorption and dissolution. Geochim. Cosmochim. Ac. 72, 3241-3257 (2008).

26. Khan, M., Williams, R. L. \& Williams, D. F. The corrosion behaviour of Ti-6Al-4V, $\mathrm{Ti}-6 \mathrm{Al}-7 \mathrm{Nb}$ and $\mathrm{Ti}-13 \mathrm{Nb}-13 \mathrm{Zr}$ in protein solutions. Biomaterials 20, 631-637 (1999).

27. Zhang, Y. et al. Time-dependent enhanced corrosion of Ti6Al4V in the presence of $\mathrm{H}_{2} \mathrm{O}_{2}$ and albumin. Sci. Rep. 8, 3185 (2018).

28. Wang, J. L. et al. A closer look at the in vitro electrochemical characterisation of titanium alloys for biomedical applications using in-situ methods. Acta Biomater. 54, 469-478 (2017).

29. $\mathrm{Yu}, \mathrm{F}$., Addison, O. \& Davenport, A. J. A synergistic effect of albumin and $\mathrm{H}_{2} \mathrm{O}_{2}$ accelerates corrosion of Ti6Al4V. Acta Biomater. 26, 355-365 (2015).

30. Hedberg, Y. S., Žnidaršič, M., Herting, G., Milošev, I. \& Odnevall Wallinder, I. Mechanistic insight on the combined effect of albumin and hydrogen peroxide on surface oxide composition and extent of metal release from Ti6Al4V. J. Biomed. Mater. Res. B, in press https://onlinelibrary.wiley.com/doi/abs/10.1002/ jbm.b.34182.

31. Okazaki, Y. \& Gotoh, E. Comparison of metal release from various metallic biomaterials in vitro. Biomaterials 26, 11-21 (2005).

32. Schwertmann, U. Solubility and dissolution of iron oxides. Plant Soil 130, 1-25 (1991).

33. Kocijan, A., Milošev, I. \& Pihlar, B. The influence of complexing agent and proteins on the corrosion of stainless steels and their metal components. J. Mater. Sci. Mater. M. 14, 69-77 (2003).

34. Hedberg, Y., Mazinanian, N. \& Odnevall Wallinder, I. Metal release from stainless steel powders and massive sheet-comparison and implication for risk assessment of alloys. Env. Sci. Process. Impact 15, 381-392 (2013).

35. Lewis, A. C., Kilburn, M. R., Papageorgiou, I., Allen, G. C. \& Case, C. P. Effect of synovial fluid, phosphate-buffered saline solution, and water on the dissolution and corrosion properties of CoCrMo alloys as used in orthopedic implants. J. Biomed. Mater. Res. A 73A, 456-467 (2005).

36. Merritt, K. \& Brown, S. A. Effect of proteins and $\mathrm{pH}$ on fretting corrosion and metal ion release. J. Biomed. Mater. Res. 22, 111-120 (1988).

37. Hedberg, Y. S. \& Odnevall Wallinder, I. Metal release from stainless steel in biological environments: a review. Biointerphases 11, 018901-1-018901-17 (2016).

38. Thyssen, J. P. \& Chen, J. (Eds.) Metal Allergy_From Dermatitis to Implant and Device Failure. (Springer International Publishing, Cham, 2018).

39. Yang, J. \& Black, J. Competitive binding of chromium, cobalt and nickel to serum proteins. Biomaterials 15, 262-268 (1994).

40. Tyagi, A. K. et al. IgG particle formation during filling pump operation: a case study of heterogeneous nucleation on stainless steel nanoparticles. J. Pharm. Sci. 98, 94-104 (2009).

41. Thompson, C. et al. Impact of magnetic stirring on stainless steel integrity: effect on biopharmaceutical processing. J. Pharm. Sci. 106, 3280-3286 (2017).

42. Rosenberg, A. S. Effects of protein aggregates: an immunologic perspective. AAPS J. 8, E501-E507 (2006)

43. Hedberg, Y. S. et al. Can cobalt(II) and chromium(III) ions released from joint prostheses influence the friction coefficient? ACS Biomater. Sci. Eng. 1, 617-620 (2015).

44. Liao, Y. et al. Graphitic tribological layers in metal-on-metal hip replacements. Science 334, 1687-1690 (2011).

45. Espallargas, N., Fischer, A., Igual Muñoz, A., Mischler, S. \& Wimmer, M. A. In-situ generated tribomaterial in metal/metal contacts: current understanding and future implications for implants. Biotribology 10, 42-50 (2017).

46. Arenas, M., Conde, A., De Frutos, A. \& de Damborenea, J. Electrochemical noise measurements of AISI $316 \mathrm{~L}$ during wear in simulated physiological media. Corros. Eng. Sci. Techn. 49, 656-660 (2014).

47. Swiatkowska, I. et al. Synchrotron analysis of human organ tissue exposed to implant material. J. Trace Elem. Med. Bio. 46, 128-137 (2018).

48. Gibon, E. et al. The biological response to orthopaedic implants for joint replacement: Part I: metals. J. Biomed. Mater. Res. B 105, 2162-2173 (2017).

49. Jackson, S. P. The growing complexity of platelet aggregation. Blood 109, 5087 (2007). 
Open Access This article is licensed under a Creative Commons Attribution 4.0 International License, which permits use, sharing, adaptation, distribution and reproduction in any medium or format, as long as you give appropriate credit to the original author(s) and the source, provide a link to the Creative Commons license, and indicate if changes were made. The images or other third party material in this article are included in the article's Creative Commons license, unless indicated otherwise in a credit line to the material. If material is not included in the article's Creative Commons license and your intended use is not permitted by statutory regulation or exceeds the permitted use, you will need to obtain permission directly from the copyright holder. To view a copy of this license, visit http://creativecommons. org/licenses/by/4.0/.

(c) The Author(s) 2018 